\title{
Introduction: the Humanities and Citizenship
}

\author{
Georgia Christinidis • Heather Ellis
}

Received: 4 October 2012 / Accepted: 15 October 2012 /

Published online: 9 November 2012

(C) Springer Science+Business Media New York 2012

The discourse of the knowledge (-based) economy constitutes a particular challenge for the humanities: where the role of the university is thought of in purely economic terms, the humanities must strive for legitimacy exclusively on the grounds of their ability to contribute to economic and technological development. This discourse fundamentally disempowers the humanities by neglecting their specificity and socializing function. The articles contained in this special issue seek to expand the paradigm within which the role of the humanities, both in the academy and in society more broadly, is conceptualized. Central to this is examining the changing functions which the humanities have fulfilled in different historical and cultural contexts. Historically, the rise of the humanities to prominence within the Western academy was closely linked to the emergence of the nation state and the ideal of the university as a guardian of national culture in the nineteenth century. However, in an increasingly globalized world, where the category of the nation state is progressively eroded in favor of transnational connections, this role has been fundamentally undermined. New approaches and multiple recontextualizations are therefore needed if we are to accurately assess the position and function of the humanities "without," in the words of Bill Readings, "recourse either to nostalgia for national culture or to the discourse of consumerism" (Readings 1996, p. 19). It was to discuss these and related questions that a number of scholars working in different areas of the humanities and social sciences, including literary studies, history, philosophy, political science, and modern languages, gathered at the Centre for British Studies in Berlin in September 2011 to take part in the workshop: "The Changing Role of the Humanities in the Academy and Society," generously funded by the Fritz Thyssen Foundation. ${ }^{1}$ To discuss the

\footnotetext{
${ }^{1}$ In order to carry on discussions of the changing role of the humanities arising from the conference, in addition to this special issue, the editors have also set up a blog entitled "Why Humanities?" which can be visited at http://why-humanities.blogspot.de/

G. Christinidis $(\bowtie) \cdot H$. Ellis

Centre for British Studies, Mohrenstr. 60, 10117 Berlin, Germany

e-mail: georgia.christinidis@staff.hu-berlin.de

URL: http://www.gbz.hu-berlin.de/staff/staff/profil-christinidis

H. Ellis

e-mail: ellish@hope.ac.uk

URL: http://www.hope.ac.uk/staffindex/staffmembers/name,13886,en.html
} 
challenges currently facing the humanities and discuss possible future directions from as global a perspective as possible, it was important that participants come from a wide range of countries including the USA, the UK, Germany, Norway, Finland, and Greece. In many ways, the socializing role of the humanities (in particular, in relation to the education of citizens) has suffered greatly due to its connection with the era of the nation state and nationalism in the late nineteenth and early twentieth centuries. The role played by the humanities during this period is often seen (and criticized) as serving nationalist (even racist or fascist) ideologies. It is this kind of political "baggage" as well as the increasingly dubious relevance of the national paradigm, which has caused the socializing role of the humanities to seem defunct. In addition, against the background of globalization and the discourse of the knowledge-based economy, in particular, the humanities (along with the social sciences) have come to be valued according to the model of the natural and technological sciences, namely in terms of their potential for contributing to innovation and economic productivity. When judged in this way, much of the content of the humanities appears useless, and, at best, they are valued in terms of developing transferable skills such as organizational ability and the analysis of documents. Although it is important to stress the inherent value of the content of the humanities as a set of subjects, it is the belief of the editors of and the contributors to this special issue that the greatest value of the humanities lies in their socializing role, not because they inculcate a specific set of national values, but in the critical stance and reflexive approach which they (perhaps uniquely) can promote in those who study them. The intimate relationship between the university, the humanities, and citizenship was captured well by Edward Said when he addressed the new class of graduates at the American University in Cairo in 1999 in a lecture entitled "On the University":

Perhaps you feel that, now you have finished your course of study, you need no longer be concerned with the university, except as an alumnus. That would be a mistake. You are not only graduates and former students, you are citizens, and citizenship requires resolute attention to what is most important about the life of your society (Said 2005, pp. 29-30).

It is our conviction that the humanities (as a set of disciplines and as an idea or an approach to life) have a vital role to play in helping to identify and to protect "what is most important about the life of our society." It was thus a central aim of the conference out of which this special issue arose not simply to discuss the ongoing crisis of the humanities (which many other events have done) but also to use our discussions creatively to suggest tangible ways in which the humanities might be drawn upon to foster the active and critical citizenship crucial to the continued existence of democratic societies as well as to peaceful and productive coexistence in a global age. This is, moreover, the aim of the eight authors whose essays make up this special issue and who engage not only with the causes of the current crisis but also with the question of how the humanities might act in innovative and creative ways to enrich not simply the academy but the life of society as a whole.

Thus, many of the contributors look back in time at the roles which philosophy and education, more broadly, played in periods before the emergence of the nation state. In particular, several articles focus on the ancient world with the aim of reconceptualizing the role which the humanities might play in a world often considered as post- 
national. In her essay, "The Right to University: The Question of Democracy in the Polis at a Time of Crisis," Asimina Karavanta explores the complex relationship between the academy and the polis at the time of Socrates and Plato as well as today, arguing that it is of the essence of democracy to remain open to that which lies beyond its boundaries and that the academy, properly understood, fulfills a vital function in mediating this relationship with the excluded. In his piece, entitled "Symbiotic Learning Systems-Reorganizing and Integrating Learning Efforts and Responsibilities Between Higher Educational Institutions (HEIs) and Work Places," Olav Eikeland draws on both Aristotelian and Platonic notions of dialogue and the ancient Greek understanding of skhole (or school) as "a practically embedded reflective place for dialogue" to characterize the quality of learning needed to enrich modern work life. Georgia Christinidis and Heather Ellis, meanwhile, explore ancient ideals of a liberal education in an attempt to defamiliarize and, thereby, to criticize the modern discourse of the knowledge-based economy in "Knowledge, Education and Citizenship in a Pre- and Post-National Age."

The recurrent references to the ancient world are symptomatic of a broader use of comparative and historicizing approaches for the purpose of defamiliarization by the contributors to this special issue. In their analysis of "Competitiveness, the Knowledge-Based Economy, and Higher Education," Ngai-Ling Sum and Bob Jessop identify the key stages of the development of the modern notions of "competition/ competitiveness" and the "knowledge-based economy" and situate them firmly within their historical, cultural, and discursive contexts. Such contextualization is crucial to revealing the constructed and contingent nature of hegemonic economic concepts which are often taken as given. In his essay, "One, Two or Three Cultures? Humanities versus the Natural and Social Sciences in Modern Germany," Roberto Sala undertakes a similar task of historicization, showing the ways in which the humanities themselves should be viewed as a context-dependent, flexible category which has shifted considerably in terms of the subjects it has included within its remit and the functions which have been assigned to it over time. Nearly all the articles engage in discursive analysis, exploring a number of different hegemonic discourses which may be considered disciplinary in a Foucauldian sense: "internationalization" and "globalization" in Asimina Karavanta's article, as well as "the knowledge-based economy," "cluster paradigm," and "knowledge brands" in Ngai-Ling Sum's and Bob Jessop's analysis.

Another issue which a number of articles explore in some detail is the question of whether a certain distance is desirable between the academy and society (or the polis). Both Asimina Karavanta and Olav Eikeland reject Plato's insistence that philosophy must be completely separated from the institutions of the polis for its own protection; yet both remain aware that a certain distance is necessary for maintaining academic freedom and as a precondition of a critical stance. Asimina Karavanta urges the university to develop as a "post-national and trans-modern" institution engaging "critically with the current social and political transformations of national communities and the development of intercultural and interdiasporic communities within them." From a different perspective, Olav Eikeland also insists on the inextricable intertwining of knowledge and tekhne, and the need for a rapprochement between education and the work place which does not collapse the former into the day-to-day demands of the latter. Short-term fixes to pressing problems such as management consultants offer should be replaced with regular and embedded opportunities for 
self-reflection, "back-stage," as he terms it, where workplace hierarchies are temporarily set aside. The problematic status of institutional spaces and their relationship with power structures is also highlighted in Susan Bruce's article, "The Hector Hypothesis: Disciplines, Difficulty, and Democracy," where the most significant interaction between a particular student and the lecturer takes place in the seminar break, "back-stage," if you will.

Distance is a precondition for a stance that goes beyond self-interest, which is central to the critical function of the humanities. This is particularly highlighted in Georgia Christinidis's and Heather Ellis's analysis of the role which Stoicism played in ancient ideals of a liberal education, as well as in Susan Bruce's emphasis on the importance of "contesting a claim that you believe to be wrong no matter who makes it." It is this setting aside of self-interest that enables the humanities to act as a site of empowered dissent. In these respects, the humanities and the values they foster are furthermore in profound conflict with the central value accorded to self-interest in liberal ideologies, an idea analyzed in depth in Georgia Christinidis's and Heather Ellis's reading of liberal concepts of citizenship and of the crisis of the humanities as one that centers on the contested relationship between the economic and the political realms.

The articles in this special issue have been deliberately structured to help readers understand the key positions and arguments which emerged from the conference. Susan Bruce's article is placed first because it sets out in clear terms the kinds of questions which the humanities, both as a set of disciplines and as a critical approach, ask. It also usefully draws on analysis of a concrete classroom situation to exemplify the ways in which a humanities approach can develop critical thinking, discursive analysis, and self-reflection in students from many different backgrounds. In common with many of the other contributions here, Susan Bruce stresses the humanities' ability to facilitate a dedicated space for reflective discussion, what she terms "an argumentational method whose fostering is fundamental to the health of liberal democracy." She shows how humanities students learn to question what they previously took for granted, to appreciate that language can have a multiplicity of meanings and is "rarely transparent or straightforward."

In the second article, by Ngai-Ling Sum and Bob Jessop, this questioning of language and discourse, which is arguably one of the most important qualities and characteristics of the humanities, is applied to the current financial crisis which has served to exacerbate dramatically the economic logic which the humanities are subjected to - as government funding fails and private money is harder to come by. The critical and discursive analysis which lies at the heart of the humanities is combined by Jessop and Sum with a classical political economy approach to deepen our understanding of the financial crisis and its impact on the academy. Arguing that the economy itself is made up of both material and discursive factors, they stress the "performative force of economic imaginaries" and reveal the constructed and contingent nature of prominent ideas including the "knowledge-based economy," "competitiveness," and "innovation."

Adopting a similar approach, Mina Karavanta's essay examines a crisis not just in the economy but also in society and politics, showing that the two are intimately related. She locates the origins of the "humanities approach" in Socratic philosophy, particularly in the idea that while the academy should not be subject to the will of politicians or the market, it should not be artificially isolated from society or the 
demos; indeed, the withdrawal of the academy from the city that took place under Plato may ultimately compromise the role of the academy as the embodiment of that critical spirit of self-reflection which lies at the heart of democracy.

In the fourth article, Georgia Christinidis and Heather Ellis draw further comparisons with the ancient world with a particular focus on the relationship between concepts of a liberal education and ideals of citizenship. This is, in part, intended not only to defamiliarize and thereby "other" liberal and neo-liberal concepts of education and citizenship but also to help search for a potential model, which, successful in a pre-national context, might be used to inspire new ideas for what is ever more frequently described as a post-national world. In particular, we sought to find ways to discursively counteract the current depoliticization of society and the economization of politics which lie at the heart of the current crisis of the humanities.

While Asimina Karavanta's article examines the ways in which the polis and the academy became separated over time, and Georgia Christinidis's and Heather Ellis's piece looks at the changing relationship between the political and economic spheres, the fifth article by Roberto Sala explores historically the ways in which the discourse of the humanities has become detached from the natural sciences, from the spheres of the economy and politics. It looks at a crucial period in the history of scholarship, beginning with the industrial revolution, and argues for its impact on the development of disciplinary boundaries. In particular, he highlights the growing influence of a notion of an unbridgeable gap between the humanities and the natural sciences, the myth of "two cultures."

The final contribution by Olav Eikeland takes issue with the (as he sees it) unnecessary and undesirable separation between educational institutions and the workplace, manifested perhaps most clearly in the distinction still often insisted upon between "vocational" and "liberal" education. Moreover, through a discussion of his own concept of "symbiotic learning systems," he offers a tangible suggestion for how this separation might be overcome. Unlike some of the other contributors, he does not use ancient philosophy to argue for a withdrawal from the knowledge-based economy; rather, he seeks to humanize it, by displacing the economic telos with an Aristotelian-inspired notion of virtue in which every practice is developed to the highest possible point of excellence. His suggestion is, as far as possible, to integrate the humanities approach and a space for critical thinking within firms, businesses, and workplaces and transform them (and their workers) from within.

This special issue is in no way intended to constitute the last word on how the many challenges facing the humanities should be tackled (and hopefully surmounted); it does, however, hope to go beyond the usual discussion of the causes of the crisis. Instead, the various articles included here have tried (in line with the aims of the original conference) to offer thoughtful, realistic, and above all, positive suggestions for reconceptualizing the complex and multifaceted role of the humanities in today's world.

\section{References}

Readings, B. (1996). The university in ruins. Cambridge: Harvard University Press.

Said, E.W. (2005). On the university. Journal of Comparative Poetics (Special Issue: Edward Said and Critical Decolonization) No. 25, 26-36. 